\title{
Changes in Body Image in Patients with Prostate Cancer over 2 Years of Treatment with a Gonadotropin-Releasing Hormone Analogue (Triptorelin): Results from a Belgian Non-Interventional Study
}

\author{
Hans van den Driessche ${ }^{1} \cdot$ Pieter Mattelaer $^{2} \cdot$ Peter van Oyen $^{3} \cdot$ Wouter Marchand $^{4} \cdot$ \\ Ovadia Bar-Moshé $^{5} \cdot$ Luc Merckx $^{6}$ - Ignace Billiet ${ }^{7}$ - Patrick Cabri ${ }^{8}$. \\ Pascal Maisonobe $^{8} \cdot$ Vincent De Ruyter $^{9} \cdot$ Johan Braeckman $^{10}$
}

Published online: 13 May 2016

(c) The Author(s) 2016. This article is published with open access at Springerlink.com

\begin{abstract}
Background Androgen deprivation therapy has been associated with worsened body image in prostate cancer patients. Body image and physical presentation changes were investigated in patients receiving a gonadotropin-releasing hormone analogue (triptorelin) as part of treatment for locally advanced or metastatic prostate cancer.

Objective The aim was to evaluate the changes in selfperception of the body and to assess the relationship of these changes over a period of 2 years in men treated with triptorelin as primary therapy for advanced or locally advanced prostate cancer.

Methods Data were collected for 2 years in accordance with routine clinical practice. Body image was assessed using the body image scale (BIS). Patient body mass index (BMI) and waist circumference were also measured.

Results BIS and BMI data for both baseline and a least one post-baseline visit were available for 98 of the 145 patients enrolled. The median change in BIS score for patients
\end{abstract}

Vincent De Ruyter

Vincent.de.ruyter@ipsen.com

CVBA Medizorg, Bredene, Belgium

AZ Damiaan, Campus St Jozef, Oostende, Belgium

AZ St Jan, Brugge, Belgium

AZ Delta, Roeselare, Belgium

5 Avenue Winston Churchill 5, Brussels, Belgium

6 AZ St Lucas, Ghent, Belgium

7 AZ Groenige, Campus Sint-Maarten, Kortrijk, Belgium

8 Ipsen Pharma, Boulogne Billancourt, France

9 Ipsen NV, Guldensporenpark 87, 9820 Merelbeke, Belgium

10 UZ Brussel, Brussels, Belgium assessed around 12 or 24 months after baseline and at the last observation was zero, indicating no body image deterioration in at least half of patients. Statistically significant BIS score increases were detected in assessments around 6,12 and 18 months, but not after 2 years, indicating some patients experienced body image deterioration at some point during treatment. Changes in BMI from baseline were modest and generally not statistically significant. Waist circumference increased during the study (mean \pm standard deviation increase of $1.00 \pm 5.01 \mathrm{~cm}$ at the last observation). Positive correlations were determined between increases in BIS score and both BMI and waist circumference $(r=0.235$ and 0.267 , respectively; $p=0.020$ and 0.008 ) at the last observation for all patients, as well as during the second year of the study. Conclusions Most patients did not experience clinically meaningful worsening of body image perception during the study. BMI and waist circumference had a modest impact on body image during study year 2 .

\section{Key Points}

The majority of prostate cancer patients treated for over 2 years with triptorelin did not experience a clinically meaningful worsening of body image.

Changes in BMI and waist circumference had a modest impact on body image.

\section{Introduction}

Prostate cancer is the most commonly occurring new cancer in European men, with an estimated 416,700 new cases in 2012, corresponding to an age-standardised 
incidence of 96.0 per 100,000 [1]. Despite the reported high incidence of prostate cancer, the mortality is relatively low (age-standardised mortality rate of 19.3 per 100,000) [1], with 5-year survival rates in excess of $80 \%$ reported in most European countries in the period between 2005 and 2009 [2]. Both the incidence of and the survival rate from prostate cancer are increasing [1,2], leading to a growing population of cancer survivors with long-term comorbidities (increased risk for diabetes, bone deterioration and increase in high-density lipoprotein cholesterol) associated with prostate cancer and its treatment [3].

Proliferation of prostate cancer cells is mediated by the androgen receptor, which is primarily activated by dihydrotestosterone, an active metabolite of testosterone [4]. Consequently, androgen deprivation therapy (ADT) is one of the major treatments for advanced or metastatic prostate cancer, with almost half of all prostate cancer patients receiving some form of ADT during the course of their disease [5]. The side effects of ADT therapy are wellcharacterised, and include osteoporosis and loss of libido, as well as increased body fat and decreased muscle mass [6-10]. The physical changes in patients treated with ADT have been associated with worsening body image perception, and a concomitant negative impact on quality of life [11].

A previous study investigating body image perception in patients with prostate cancer reported that patients receiving ADT experienced significantly greater dissatisfaction with their body image than ADT-naïve patients [11]. In the overall study population, increased body image dissatisfaction correlated to higher body mass index (BMI) [12]. Harrington et al. [12] measured body image perception using the body image scale (BIS), a validated, reliable questionnaire for use with cancer patients [13]. The BIS contains ten Likert-like items relating to self-consciousness about appearance, physical attractiveness, dissatisfaction with appearance, feeling less feminine/masculine, finding it difficult to look at oneself naked, feeling less sexually attractive, avoiding people due to one's appearance, feeling treatment has left the body less whole, dissatisfaction with one's own body, and dissatisfaction with the appearance of a scar [13].

Available ADT treatments for locally advanced or metastatic prostate cancer include triptorelin (Decapeptyl ${ }^{\circledR}$, Ipsen), a gonadotropin-releasing hormone (GnRH) analogue. Chronic and continuous triptorelin administration leads to decreased luteinising hormone and suppression of testicular steroidogenesis $[14,15]$. The purpose of the current observational study was to investigate changes in body image perception in patients with locally advanced or advanced prostate cancer receiving triptorelin as body image seems to play an important role in these patients [11]. Body image was assessed using a modified nine-item version of the BIS (excluding the question relating to the appearance of a scar, which was not relevant in this context). In addition, changes in BMI and waist circumference were measured to assess whether changes in body image perception were related to changes in physical presentation experienced by patients receiving triptorelin.

\section{Methods}

The present study was a prospective, observational, multicentre study conducted between 25 January 2010 and 30 April 2014 at 18 sites in Belgium, the majority being hospitals. Sites were selected after a qualification visit for both the study target population and logistics to conduct clinical studies. The study received ethics committee approval as required by Belgian law for non-interventional studies.

\subsection{Patients}

The study enrolled adult men aged 50 years or older with locally advanced or metastatic prostate cancer who were scheduled to receive triptorelin. As this was a non-interventional study, the decision to prescribe triptorelin was made prior to, and independently from, the decision to enrol a patient in the study. Patients receiving, or scheduled to receive, docetaxel chemotherapy, radical prostatectomy or radiotherapy were excluded from the study; as were patients who had received any investigational drug in the 3 months before study entry. Patients who had radical prostatectomy or radiotherapy prior to inclusion in the study were allowed to participate. Patients were followed in the study until their routine hospital visit closest to study week 104.

\subsection{Study Visits}

As this was an observational study, the timing of study visits was not determined in the study protocol, but reflected the normal interaction between patient and physician. Patients were assessed during their usual hospital visits. To allow changes in measurements to be assessed over time, study visits were allocated to 'time windows' of approximately 90 days, as follows: day 1 (baseline); month (M) 3 (target day 92); M 6 (target day 184); M 9 (target day 275); M 12 (target day 366); M 15 (target day 458); M 18 (target day 549); M 21 (target day 640) and M 24 (target day 732). If more than one visit fell into the same window, the closest to the target day was retained. As the timing of visits was according to routine practice at the individual study site, not all patients were assessed during each time window. In addition, data for the 
non-baseline study visit nearest week 104 (last observation) were summarised for all patients.

\subsection{Assessments}

Patient body image perception was assessed with a modified version of the BIS [13]. The full BIS questionnaire was used, with the exception of the question, "Have you been dissatisfied with the appearance of your scar?" Responses to individual questions were on a $0-3$ scale $(0=$ not at all, 3 = very much), and a total BIS score was calculated for all nine items used, to give a score out of 27 (where higher scores indicate worse body image perception).

Patient height, weight and waist circumference were measured at baseline. Weight and waist circumference were measured at subsequent study visits. Study data were presented using summary statistics. Measurements at each time window and at the last observation were compared with baseline values by paired $t$ test. Correlations between changes in BMI and waist circumference and changes in total BIS score were determined by Pearson correlation coefficient. Student's $t$ test was used to compare Pearson correlation coefficients with 0 .

\section{Results}

A total of 145 patients provided signed informed consent and were enrolled in the study, 138 of whom received triptorelin. Of the 138 patients treated, 106 completed the study. Patient flow through the study is summarised in Fig. 1. Total BIS score and BMI data were available for a total of 98 triptorelin-treated patients. Demographic and baseline disease data for these patients are presented in Table 1. The patients assessed in this study were predominantly elderly [mean \pm standard deviation (SD) age $77.8 \pm 7.1$ years] and the majority (98\%) were Caucasian. The most common indication for treatment was first-line

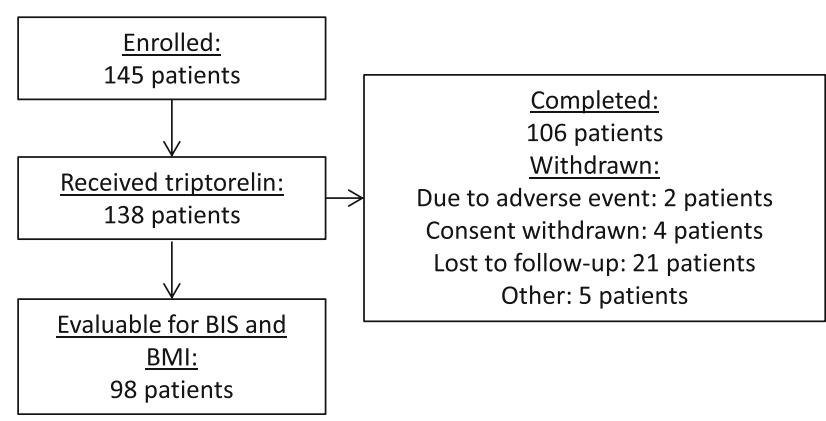

Fig. 1 Study flowchart: patient disposition. Data were evaluated for the 98 patients who received triptorelin and had body image scale (BIS) and body mass index (BMI) data available for baseline and at least one other study visit
Table 1 Study population characteristics (age, race, Gleason score, indication for triptorelin treatment, dose of triptorelin)

\begin{tabular}{|c|c|c|}
\hline Characteristic & Category/statistic & $\begin{array}{l}\text { Total } \\
\text { population } \\
(N=98)\end{array}$ \\
\hline \multirow[t]{3}{*}{ Age, years } & Mean \pm SD & $77.8 \pm 7.1$ \\
\hline & Median & 79.0 \\
\hline & Range & $57-94$ \\
\hline \multirow[t]{2}{*}{ Race, $n(\%)$} & Asian & $2(2.0)$ \\
\hline & Caucasian & $96(98.0)$ \\
\hline \multirow{3}{*}{$\begin{array}{l}\text { Time since first } \\
\text { diagnosis, } \\
\text { years }\end{array}$} & Mean \pm SD & $4.0 \pm 4.7$ \\
\hline & Median & 2.0 \\
\hline & Range & $0-19$ \\
\hline \multirow{4}{*}{$\begin{array}{l}\text { Gleason score, } \\
n(\%)\end{array}$} & $\leq 6$ & $29(31.2)$ \\
\hline & 7 & $35(37.6)$ \\
\hline & $8-10$ & $29(31.2)$ \\
\hline & Unknown & 5 \\
\hline \multirow{8}{*}{$\begin{array}{l}\text { Indication, } \\
n(\%)\end{array}$} & Adjuvant after TURP & $6(6.1)$ \\
\hline & $\begin{array}{l}\text { Adjuvant after radiotherapy/ } \\
\text { brachytherapy }\end{array}$ & $5(5.1)$ \\
\hline & $\begin{array}{l}\text { Rising PSA after radical } \\
\text { prostatectomy }\end{array}$ & $12(12.2)$ \\
\hline & $\begin{array}{l}\text { Rising PSA after radiotherapy/ } \\
\text { brachytherapy }\end{array}$ & $12(12.2)$ \\
\hline & $\begin{array}{l}\text { Locally advanced, first-line } \\
\text { therapy }\end{array}$ & $46(46.9)$ \\
\hline & $\begin{array}{l}\text { Locally advanced, after } \\
\text { antiandrogen monotherapy }\end{array}$ & $1(1.0)$ \\
\hline & Metastatic, first line & $9(9.2)$ \\
\hline & Other/multiple & $7(7.1)$ \\
\hline \multirow{3}{*}{$\begin{array}{l}\text { Triptorelin dose } \\
\text { prescribed, } \\
n(\%)\end{array}$} & $3.75 \mathrm{mg}$ & $8(8.2)$ \\
\hline & $11.25 \mathrm{mg}$ & $85(86.7)$ \\
\hline & $22.50 \mathrm{mg}$ & $5(5.1)$ \\
\hline
\end{tabular}

$P S A$ prostate specific antigen, $S D$ standard deviation, TURP transurethral resection of the prostate

therapy for locally advanced prostate cancer (46.9\% of patients), and the most frequently prescribed triptorelin dose was $11.25 \mathrm{mg}$.

Changes in total BIS score, BMI and waist circumference from baseline are presented in Fig. 2. Higher BIS scores indicate worsening body image. There was considerable variation in the number of patients assessed at each time window, with most patients being assessed at M 12 and M 24. As this is a non-interventional study, this reflects clinical practice at the study sites. Changes in total BIS score, BMI and waist circumference at M 12, M 24 and the last observation are summarised in Table 2. At baseline, both mean and median BMI were consistent with recorded mean values for adult Belgian males (26.78 kg/m $\mathrm{m}^{2}$ in 2008 [16]). Mean and median waist circumference was below $102 \mathrm{~cm}$ at baseline, which is considered the point beyond which there are considerable 

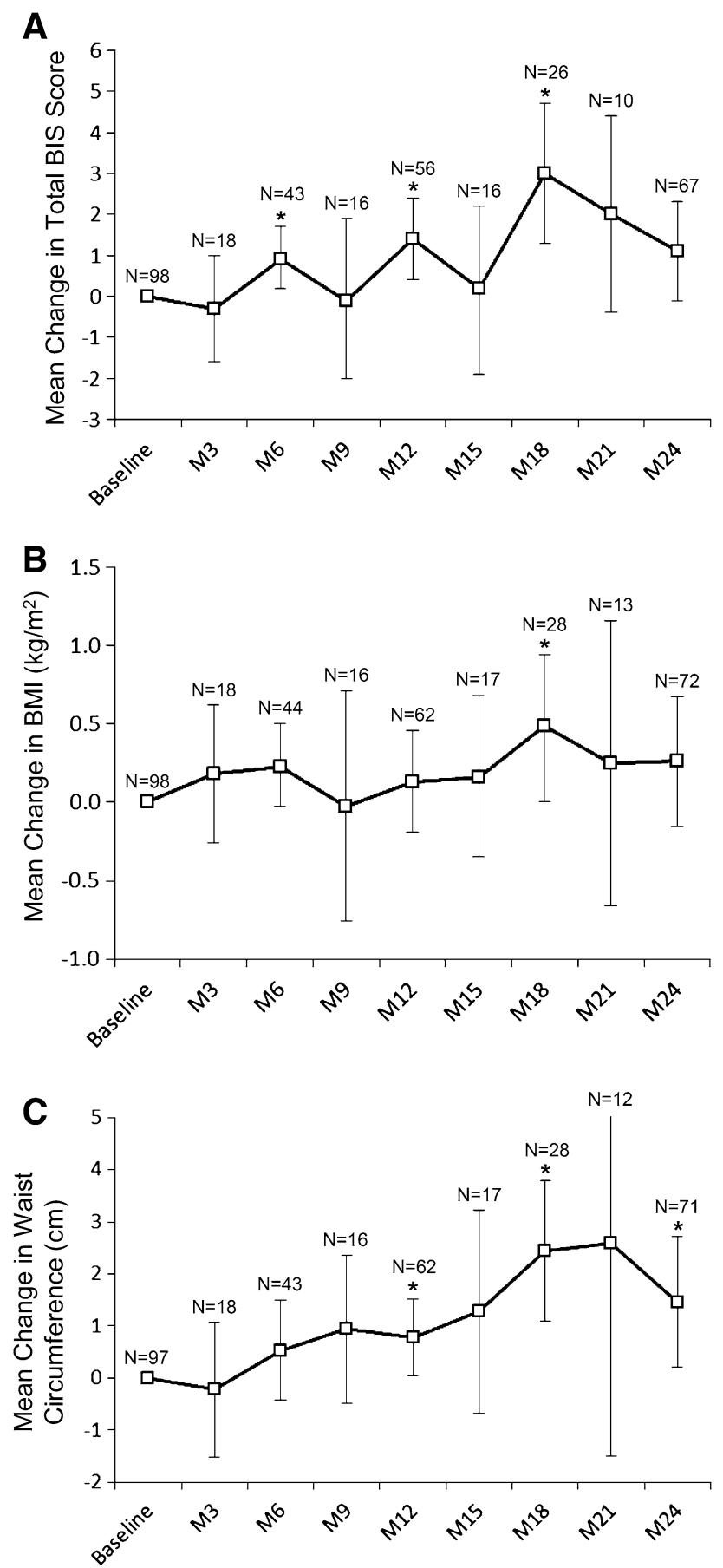

Fig. 2 Mean change in a total body image scale (BIS) score, $\mathbf{b}$ body mass index (BMI) and $\mathbf{c}$ waist circumference at each time window. Error bars represent $95 \%$ confidence intervals. Asterisk indicates a statistically significant change from baseline $(p<0.05) . M$ month

health risks associated with being overweight for a male patient [17].

Notably, the median change in total BIS score recorded at both M 12 and M 24 was 0.0. At the last observation, the median change recorded for the whole population was also 0.0 , indicating that at least half of the patients in the study did not perceive any worsening in body image (Table 2). Despite this, statistically significant increases in mean \pm SD BIS score were recorded at M $6(0.9 \pm 2.5$, $p=0.018), \quad \mathrm{M} 12(1.4 \pm 3.8, \quad p=0.008) \quad$ and $\mathrm{M} 18$ $(3.0 \pm 4.2, p=0.001$; Fig. $2 \mathrm{a})$ as well as at the last observation for all patients $(1.1 \pm 4.5, \quad p=0.017$; Table 2). These data indicate that some patients reported significant worsening of body image at these time windows and at the end of the study. Interestingly, smaller mean increases from baseline BIS score were recorded at M 24 $(1.1 \pm 4.9)$ compared with the preceding time windows, and this change was not statistically significant ( $p=0.068)$, suggesting that patients may experience some acceptance of body image changes over 2 years (Fig. 2a).

When responses to individual BIS questions were compared between baseline and the last observation for all patients (see Fig. 3), mean scores increased notably during triptorelin treatment for seven of the nine items. Exceptions included question 1 ("Have you been feeling self-conscious about your appearance?"), where mean scores were lower at the end of study compared to baseline, and question 7 ("Did you avoid people because of the way you felt about your appearance?"), where mean scores were similar at baseline and the last observation. The lack of change in mean score for question 7 is not surprising given the nature of the body image changes experienced by patients in this study (Fig. 2b, c). Responses to question 1 at baseline and the last observation suggest a degree of self-consciousness due to appearance at baseline, which reduced at the last observation.

Mean values for BMI were comparable to baseline for most time windows (Fig. 2b). A statistically significant increase in BMI from baseline was recorded during M 18 only (mean $\pm \mathrm{SD} 0.47 \pm 1.20 \mathrm{~kg} / \mathrm{m}^{2}, p=0.048$ ). There was a trend towards increasing waist circumference throughout the study (Fig. 2c), with statistically significant mean $\pm \mathrm{SD}$ increases in waist circumference recorded at M $12(0.78 \pm 2.94 \mathrm{~cm}, p=0.041)$, M $18(2.45 \pm 3.48 \mathrm{~cm}$, $p<0.001)$ and M $24(1.45 \pm 5.32 \mathrm{~cm}, p=0.024)$. Weak but statistically significant correlations were calculated between changes in BIS and changes in both BMI and waist circumference at M $24(r=0.300$ and 0.331 , respectively; $p=0.015$ and 0.007$)$ and the last observation $(r=0.235$ and $0.267 ; p=0.020$ and 0.008 ), but not at M 12 (Table 2), suggesting that changes in BMI and waist circumference contributed to patients body image perception during the second year of treatment.

\section{Discussion}

The median change in total BIS score from baseline for patients assessed at approximately 12 and 24 months and at the last observation for all subjects was zero. This indicates 
Table 2 Change from baseline in physical presentation characteristics

\begin{tabular}{|c|c|c|c|c|c|}
\hline \multirow[t]{2}{*}{ Characteristic } & \multirow[t]{2}{*}{ Statistic } & \multirow[t]{2}{*}{ Baseline } & \multicolumn{3}{|c|}{ Change from baseline } \\
\hline & & & M 12 & M 24 & Last observation \\
\hline \multirow[t]{5}{*}{ BIS } & $N$ & 98 & 56 & 67 & 98 \\
\hline & Mean \pm SD & $3.0 \pm 3.8$ & $1.4 \pm 3.8$ & $1.1 \pm 4.9$ & $1.1 \pm 4.5$ \\
\hline & Median & 2.0 & 0.0 & 0.0 & 0.0 \\
\hline & Range & $0-19$ & -14 to 9 & -16 to 13 & -16 to 13 \\
\hline & $P$ value & - & 0.008 & 0.068 & 0.017 \\
\hline \multirow[t]{6}{*}{ BMI $\left(\mathrm{kg} / \mathrm{m}^{2}\right)$} & $N$ & 98 & 62 & 72 & 98 \\
\hline & Mean \pm SD & $26.82 \pm 2.04$ & $0.13 \pm 1.27$ & $0.26 \pm 1.75$ & $0.09 \pm 1.70$ \\
\hline & Median & 26.20 & 0.04 & 0.39 & 0.00 \\
\hline & Range & $18.2-38.8$ & -5.0 to 4.3 & -6.7 to 4.1 & -6.7 to 4.1 \\
\hline & $P$ value & - & 0.412 & 0.209 & 0.621 \\
\hline & Pearson correlation $^{\mathrm{a}}$ ( $p$ value) & - & $0.117(0.392)$ & $0.300(0.015)$ & $0.235(0.020)$ \\
\hline \multirow[t]{6}{*}{ Waist circumference $(\mathrm{cm})$} & $N$ & 97 & 62 & 71 & 97 \\
\hline & Mean \pm SD & $98.59 \pm 14.23$ & $0.78 \pm 2.94$ & $1.45 \pm 5.32$ & $1.00 \pm 5.01$ \\
\hline & Median & 98.00 & 0.00 & 1.00 & 0.70 \\
\hline & Range & $64.0-139.0$ & -8.0 to 8.0 & -11.0 to 16.5 & -11.0 to 16.5 \\
\hline & $P$ value & - & 0.041 & 0.024 & 0.052 \\
\hline & Pearson correlation $^{\mathrm{a}}$ ( $p$ value) & - & $0.234(0.083)$ & $0.331(0.007)$ & $0.267(0.008)$ \\
\hline
\end{tabular}

$B I S$ body image scale, $B M I$ body mass index, $M$ month, $S D$ standard deviation

${ }^{a}$ With change in total BIS score

Fig. 3 a Change in mean score between baseline and last observation for each item of the modified body image scale (BIS) questionnaire.

b Questions in the BIS used. Adapted from Hopwood et al. [13]. An increase in BIS score indicates worsening of body image

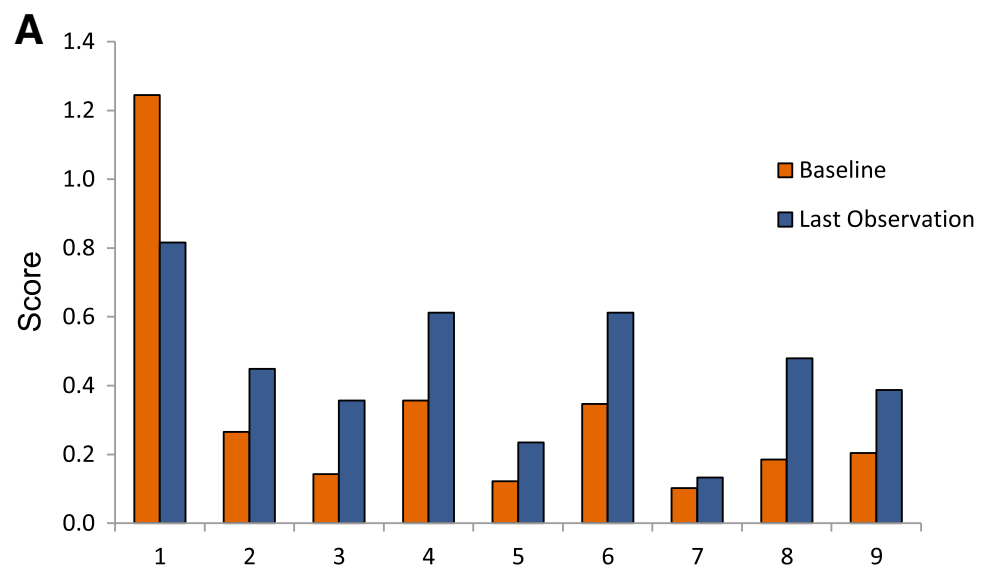

B BIS Question

1. Have you been feeling self-conscious about your appearance?

2. Have you felt less physically attractive as a result of your disease or treatment?

3. Have you been dissatisfied with your appearance when dressed?

4. Have you been feeling less masculine as a result of your treatment?

5. Did you find it difficult to look at yourself naked?

6. Have you been feeling less sexually attractive as a result of your disease or treatment?

7. Did you avoid people because of the way you felt about your appearance?

8. Have you been feeling the treatment has left your body less whole?

9. Have you felt dissatisfied with your body? that at least half of patients assessed did not report worsening body image perception at these time points. Statistically significant mean increases in BIS score were recorded during some time windows and the last observation, suggesting that, while body image remained unchanged or improved for most patients, some patients did experience worsening of body image perception at some point during triptorelin treatment. 
Body image has been associated with quality of life in patients with prostate cancer [11, 18]. Patients receiving treatment for prostate cancer typically experience a series of physical changes that may impact body image, including reduced penile length, reduced lean muscle mass and increased body fat $[8,19]$. In a study of body image perception in prostate cancer patients, those receiving ADT experienced worse body image perception, and negative body image correlated with higher BMI [12]. It is unclear from the study by Harrington et al. [12] the extent to which the differences between ADT-treated and ADT-naïve patients were due to the different treatments received, as patient disease parameters were not presented.

Where statistically significant mean changes in BIS score were reported, these were generally low in the context of a 27-point scale, with mean increases between 0.9 (M 6) and 3.0 (M 18). There are no publications indicating what constitutes a clinically meaningful increase in BIS score. However, the mean scores measured throughout the study were generally low and consistent with patients answering "not at all" to most of the items in the BIS questionnaire, indicating that patients had a generally positive perception of body image during this study. In addition, while significant changes in total BIS score were reported for patients assessed at M 6, M 12 and M 18, increases in BIS score appeared to diminish by $\mathrm{M} 24$, where changes from baseline were no longer statistically significant. This finding could be interpreted as patients developing some acceptance of the physical changes they are undergoing. However, as not all patients were assessed during each time window, comparisons of BIS score between windows should be interpreted with caution.

Currently, the BIS is the only validated tool for assessing body image in cancer patients. For this study, the modified BIS (discounting the question regarding the appearance of a scar) was the most appropriate instrument to use in this study since only $12.2 \%$ of the patients underwent a radical prostatectomy. In the future, more suitable patient-reported outcomes could be developed to address the potential impact of physical changes experienced by patients receiving treatment for prostate cancer.

When changes in individual items of the BIS were considered in the current study, mean scores indicated worsening body image in all but two aspects investigated in the questionnaire (avoiding interaction with people and feeling self-conscious about one's appearance). Given the nature and extent of the physical presentation changes experienced by patients during this study, the finding that there was little change in the number of patients who avoided people because of the way they felt about their appearance at their last observation compared with baseline is perhaps unsurprising. Interestingly, patients appeared to report feeling less self-conscious about their appearance at their last observation compared with baseline. The responses to this question indicated that this was the biggest contributor to negative body image at baseline and last observation (Fig. 3a). The reasons for this change are unclear, but this suggests that the factors affecting body image in prostate cancer patients are complex, and may change over time.

In the current study, a weak correlation was detected between increase in BIS score and increase in BMI at the last observation, and in the M 24 time window, suggesting that changes in body image are partly linked to changes in BMI after prolonged treatment in patients receiving triptorelin for prostate cancer.

Interestingly, the mean change in BMI between baseline and the last observation in this study was not statistically significant, and there was no change in the median BMI (Table 2). Statistically significant increases in BMI from baseline were measured for patients assessed at M 18 only (Fig. 2b), suggesting that most patients receiving triptorelin did not experience notable weight gain during this study.

The risk of weight gain with ADT is significantly higher in patients who are obese (BMI $\geq 30.0 \mathrm{~kg} / \mathrm{m}^{2}$ ) compared with in those whose BMI indicates they are 'normal' (18.5-24.9 kg/m²) or 'overweight' (25.0-29.9 kg/m²) [20]. Although patients with BMI values as high as $38.8 \mathrm{~kg} / \mathrm{m}^{2}$ were enrolled, the mean baseline BMI recorded in this study was consistent with that for the Belgian male population [17], and the majority of patients were overweight, rather than obese, and therefore less at risk of experiencing considerable weight gain.

Waist circumference did appear to increase during the study, with statistically significant increases measured during M 12, M 18 and M 24 (Fig. 2c). Both mean and median waist circumference increased from baseline to last observation, although these increases were not statistically significant (Table 2). This finding, combined with the modest and non-significant increases in BMI experienced by patients in the study are consistent with other studies of patients receiving $\mathrm{GnRH}$ analogues, where patients experience decreased lean mass in combination with increased fatty deposits [7, 10]. These findings suggest that some patients may be at increased risk of developing 'sarcopenic obesity' [21], and that the potential for this to occur should be considered even in the absence of an increase in BMI.

Increase in total BIS score was found to correlate weakly with increase in waist circumference at the last observation, and more strongly for the M 18 and M 24 time windows ( $r=0.492$ and 0.331 , respectively). These findings suggest that changes in waist circumference predict changes in body image in patients receiving triptorelin for prostate cancer, and that waist circumference may be a better indicator of body image perception than BMI in this patient population, particularly in patients receiving triptorelin for more than 1 year. 


\section{Conclusion}

The results of this study add to the currently limited evidence base addressing issues of body image in patients with prostate cancer. The data suggest that most patients did not experience significant deterioration in body image perception, indicating that significant worsening of body image perception is most likely experienced by a minority of patients. Changes in body image were found to correlate weakly with both BMI and waist circumference. Further study, potentially in a larger population of patients, is necessary to establish which patient groups experience the largest effects in body image (and therefore potentially the greatest emotional and psychological impact on wellbeing and quality of life) during treatment with GnRH analogues.

Acknowledgments Medical writing support for the preparation of this manuscript was provided by Graham Buttrick of Insight MW (Oxford, UK) and funded by Ipsen.

Author contributions J Braeckman, V. De Ruyter, P. Cabri and H. van den Driessche were involved in the development, review and finalisation of the manuscript. P. Maisonobe was involved in the analysis of the study data. P. Mattelaer, P. van Oyen, W. Marchand, O. Bar-Moshé, I. Billiet and L. Merckx were involved in the review of the article.

\section{Compliance with Ethical Standards}

Ethical approvals This clinical study has been reviewed and received the approval of the Ethics Committee of the University Hospital of Brussels. All patients gave written informed consent prior to participation. The study has been conducted according to the ethical standards of the Declaration of Helsinki.

Conflict of interest $\mathrm{J}$ Braeckman is an advisory board member of Ipsen NV. V. De Ruyter, P. Cabri and P. Maisonobe declare that they are employees of Ipsen. H. van den Driessche, P. Mattelaer, P. van Oyen, W. Marchand, O. Bar-Moshé and I. Billiet declare that they have no conflict of interest. L. Merckx is principal investigator of another Ipsen-sponsored study (CHRONO-6).

Funding This study was sponsored by Ipsen NV (Merelbeke, Belgium).

Open Access This article is distributed under the terms of the Creative Commons Attribution-NonCommercial 4.0 International License (http://creativecommons.org/licenses/by-nc/4.0/), which permits any noncommercial use, distribution, and reproduction in any medium, provided you give appropriate credit to the original author(s) and the source, provide a link to the Creative Commons license, and indicate if changes were made.

\section{References}

1. Ferlay J, Steliarova Foucher E, Lortet-Tieulent J, et al. Cancer incidence and mortality patterns in Europe: estimates for 40 countries in 2012. Eur J Cancer. 2013;49:1374-403.
2. Allemani C, Weir HK, Carreira H, Harewood R, Spika D, Wang X-S, et al. Global surveillance of cancer survival 1995-2009: analysis of individual data for 25676887 patients from 279 population-based registries in 67 countries (CONCORD-2). Lancet 2014 [Epub ahead of print].

3. Taylor KL, Luta G, Miller AB, Church TR, Kelly SP, Muenz LR, et al. Long-term disease-specific functioning among prostate cancer survivors and noncancer controls in the prostate, lung, colorectal, and ovarian cancer screening trial. J Clin Oncol. 2012;30(22):2768-75.

4. Lamont KR, Tindall DJ. Minireview: alternative activation pathways for the androgen receptor in prostate cancer. Mol Endocrinol. 2011;25(6):897-907.

5. Meng MV, Grossfeld GD, Sadetsky N, Mehta SS, Lubeck DP, Carroll PR. Contemporary patterns of androgen deprivation therapy use for newly diagnosed prostate cancer. Urology. 2002;60(3 Suppl 1):7-11.

6. Trost LW, Serefoglu E, Gokce A, Linder BJ, Sartor AO, Hellstrom WJ. Androgen deprivation therapy impact on quality of life and cardiovascular health, monitoring therapeutic replacement. J Sex Med. 2013;10(Suppl 1):84-101.

7. Galvão DA, Spry NA, Taaffe DR, Newton RU, Stanley J, Shannon T, et al. Changes in muscle, fat and bone mass after 36 weeks of maximal androgen blockade for prostate cancer. BJU Int. 2008;102(1):44-7.

8. Isbarn H, Boccon-Gibod L, Carroll PR, Montorsi F, Schulman C, Smith MR, et al. Androgen deprivation therapy for the treatment of prostate cancer: consider both benefits and risks. Eur Urol. 2009;55(1):62-75.

9. Smith MR. Androgen deprivation therapy for prostate cancer: new concepts and concerns. Curr Opin Endocrinol Diabetes Obes. 2007;14(3):247-54.

10. Smith MR, Finkelstein JS, McGovern FJ, Zietman AL, Fallon MA, Schoenfeld DA, et al. Changes in body composition during androgen deprivation therapy for prostate cancer. J Clin Endocrinol Metab. 2002;87(2):599-603.

11. Harrington JM. Implications of treatment on body image and quality of life. Semin Oncol Nurs. 2011;27(4):290-9.

12. Harrington JM, Jones EG, Badger T. Body image perceptions in men with prostate cancer. Oncol Nurs Forum. 2009;36(2): 167-72.

13. Hopwood P, Fletcher I, Lee A, Al Ghazal S. A body image scale for use with cancer patients. Eur J Cancer. 2001;37(2):189-97.

14. Labrie F, Dupont A, Belanger A, Lachance R, Giguere M. Long term treatment with luteinising hormone releasing hormone agonists and maintenance of serum testosterone to castration concentrations. Br Med J (Clin Res Ed). 1985;291(6492):369-70.

15. Gonzalez-Barcena D, Perez-Sanchez P, Ureta-Sanchez S, Berea Dominguez H, Graef-Sanchez A, Becerril Morales M, et al. Treatment of advanced prostatic carcinoma with D-Trp-6-LHRH. Prostate. 1985;7(1):21-30.

16. Ezzati M. Mean age standardized body mass index (BMI), $\mathrm{kg} / \mathrm{m}^{2}$. Global Burden of Metabolic Risk Factors for Chronic Diseases Collaborating Group. Available online at: http://www5.imperial. ac.uk/medicine/metabolic_risks/bmi/. Accessed 09 Mar 2015.

17. Lean ME, Han TS, Morrison CE. Waist circumference as a measure for indicating need for weight management. BMJ. 1995;311(6998):158-61.

18. Taylor-Ford M, Meyerowitz BE, D’Orazio LM, Christie KM, Gross ME, Agus DB. Body image predicts quality of life in men with prostate cancer. Psychooncology. 2013;22(4):756-61.

19. Yu Ko WF, Degner LF, Hack TF, Schroeder G. Penile length shortening after radical prostatectomy: men's responses. Eur J Oncol Nurs. 2010;14(2):160-5.

20. Kim HS, Moreira DM, Smith MR, Presti JC, Aronson WJ, Terris MK, et al. A natural history of weight change in men with 
prostate cancer on androgen-deprivation therapy (ADT): results from the Shared Equal Access Regional Cancer Hospital (SEARCH) database. BJU Int. 2011;107(6):924-8.
21. Van Poppel H, Tombal B. Cardiovascular risk during hormonal treatment in patients with prostate cancer. Cancer Manag Res. 2011;3:49-55. 